\title{
Cardiovascular Changes and Cardiac Morbidity of Menopause. Effects of Hormone Replacement Therapy
}

\author{
Roberto Bassan
}

Rio de Janeiro, RJ - Brazil

\section{General and epidemiologic considerations}

The cessation of cyclic ovulation and consequent interruption of estrogen production by follicular cells in the ovaries is a natural phenomenon in women around 50 years of age, representing the menopause or climacterium. However, menopause can also result from surgical bilateral oophorectomy in a still fertile woman. Independently of its mechanism, menopause causes important metabolic and cardiovascular changes in women, as shown by several case-controlled and cohort studies. These changes do not seem to be due to differences in age or other factors, suggesting that the cause is the reduction in estrogen levels.

During a woman's fertile years, coronary artery disease is rare, with a male-to-female ratio of at least $3: 1$, for age-matched individuals. After menopause, this ratio progressively decreases reaching 1:1, at the age of 75 and above ${ }^{1}$. A 50-year-old woman has a 50\% chance of developing coronary artery disease, and a $30 \%$ chance of dying from it during the postmenopausal years ${ }^{2}$. For breast cancer, these ratios are $10 \%$ and $3 \%$, and for endometrial cancer $3 \%$ and $0.3 \%$, respectively.

Thus, coronary artery disease is the major cause of death in adult woman (as it is for man) in developed countries. Although breast cancer is responsible for 43,000 deaths annually, and lung cancer for 51,000 deaths annually of women in the United States, coronary artery disease causes 236,000 annual deaths, and 87,000 strokes ${ }^{2,3}$.

Even though there was a $20 \%$ reduction in mortality resulting from coronary artery disease in women from 1979 to 1989 , the absolute number of women dying due to this pathology continues to increase. With the progressive increase in life expectancy, the number of women older than 50 , and consequently in menopause, is much higher today than in previous decades. In the United States, the average life expectancy for women is around 80 , showing not only a higher number of postmenopausal women but also that these women will live more than one third of their lives deprived of estrogen.

Hospital Pró-Cardíaco - Rio de Janeiro

Mailing address: Roberto Bassan - Hospital Pró-Cardíaco - Rua Dona Mariana, 219 22280-020 - Rio de Janeiro, RJ - Brazil

\section{Menopause and atherosclerotic disease}

From the pathologic point of view, atherosclerotic disease occurs later in women than in men, especially in the coronary arteries. Kayan et al. ${ }^{4}$ determined that a 50 -yearold woman has $45 \%$ of her aorta area and $25 \%$ of her coronary artery area affected by the atherosclerotic process, but a man of the same age has $50 \%$ and $40 \%$, respectively. At 75 years of age, the figures are $75 \%$ of the aorta area and $55 \%$ of the coronary artery area for women and $70 \%$ and $55 \%$ for men, respectively. This shows that for postmenopausal women the speed of coronary atherosclerotic disease development is much higher than for men of the same age group, despite similar aortic involvement.

These data support the Framingham Study, which showed that acute myocardial infarction - a clinical manifestation of coronary atherosclerosis - was rarely found in women before the age of 45 , in a ratio of one woman to 40 men ${ }^{5}$. In the age group from 45 to 64 years, the number of infarctions in women was 45 times that of the younger group, but in men it was only 3.5 times, a ratio of $1: 3$ between the genders. In individuals older than 65 , the number of infarctions in women increased 2.3 times, but in men there was no difference, resulting in a ratio of 1:1.2.

Another relevant result of the difference in coronary atherosclerotic involvement in women versus men is women's higher hospital mortality rate due to acute myocardial infarction. Several studies, including ours, have demonstrated that the relative mortality risk for women is 2-3 times higher than that for men ${ }^{6-8}$. Although some studies attribute this higher mortality to the prevalence of more death risk factors, including age - because women's average age is 6-10 years higher than that of men - some authors observed that these variables only partially explain this high mortality ${ }^{6,7}$. This indicates that sexual biological factor might be an independent variable in hospital mortality risk in patients with acute myocardial infarction.

\section{Menopause and blood pressure}

Hypertension is a known risk factor for atherosclerotic disease development-especially in the coronary arteries - in both genders ${ }^{9,10}$. Epidemiologic studies have shown that until age 35 , the prevalence of hypertension is higher in men 
than in women. However, after age 60 , this ratio is inverted ${ }^{11}$. Nevertheless, morbidity and mortality for any level of hypertension are always lower in women, including the occurrence of stroke.

The effect of menopause on blood pressure levels in women is not yet well understood, but some studies seem to indicate a mild and progressive increase with the climacteric years, especially of the systolic pressure ${ }^{14-16}$. However, although age is a known factor responsible for the increase in blood pressure, the role of menopause in pressure elevation occurring in women cannot yet be quantified.

Estrogen affects systemic and local vasodilatation ${ }^{17,18}$. This effect seems to be both dependent on and also independent from the endothelium. Estrogen-receptors are found in artery walls and, when stimulated, they respond with vasodilatation ${ }^{19}$. In addition, estrogen seems to stimulate the endothelial production of nitric oxide and prostacyclin $\left(\mathrm{PGI}_{2}\right)^{20-22}$, which are strong vasodilating agents, and also to modulate the endothelial production of endothelin ${ }^{23}$, a strong vasoconstricting agent. Finally, estrogen also seems to have a blocking effect on calcium channels of the arterial wall $^{24,25}$, resulting in vasodilatation. Changes in action and production of these vasoactive substances would be responsible for some vasomotor and pressure changes observed in woman in menopause, among which is paradoxal coronary vasoconstriction (see below).

\section{Menopause and lipid changes}

Dyslipidemias, especially those causing elevation of low-density lipoprotein cholesterol (LDL) and reduction of high-density lipoprotein cholesterol (HDL) in addition to the increase of triglycerides, are related to atherosclerotic disease, acute myocardial infarction, and cardiac death ${ }^{26}$. However, in women HDL-cholesterol and triglycerides were the strongest predictive factors of coronary artery disease development, both in the Framingham Study ${ }^{27}$ and in the Lipid Research Clinics Follow-up Study ${ }^{28}$, but LDL-cholesterol was a strong predictive factor only in the former.

Serum lipid reduction studies have shown a decrease in the risk of coronary events and also the progression of atherosclerosis, even though only a few of these investigations were carried out in women ${ }^{29-32}$.

Some studies ${ }^{33,34}$ showed that premenopausal women have lower levels of serum LDL-cholesterol than do men. However, after the age of 50, women's levels increase considerably, exceeding those of men of the same age group. With regards to HDL-cholesterol, no significant change was observed in women during pre- and postmenopausal periods, but their serum levels were always higher than those of men.

The Framingham Study also demonstrated that even though total cholesterol progressively increases with age in both genders, the rise was more accelerated in women, especially after 45 years of age ${ }^{35}$.

\section{Menopause and carbohydrate metabolism}

Diabetes is considered an important risk factor for atherosclerosis and coronary artery disease, as well as for cardiac mortality. In the Framingham Study, diabetes tripled coronary artery disease risk in women, and the same was observed for cardiac mortality ${ }^{36}$. The risk for men seems to be half that for women.

The menopausal effect in carbohydrate metabolism in women is not yet well understood. An increase in serum insulin parallel to a mild glycemic elevation seems to occur, suggesting some degree of tissular resistance to insulin ${ }^{38,39}$. However, an increase in the incidence of diabetes during menopause was not confirmed.

\section{Hormone Replacement in Menopause}

\section{Effect in the risk of cardiovascular disease}

Several studies of the case-control type suggest an inverse relation between estrogen use and coronary artery disease risk and mortality in menopausal women ${ }^{40}$. However, this type of study is influenced by factors that are difficult to control and can turn into methodological bias that ends up influencing the results as well ${ }^{2}$. Cohort studies are less prone to bias, but only prospective, randomized and controlled studies answer in a more accurate way if a therapeutic form is related to an analyzed event. Unfortunately, so far there is no study of this type that has already been finished and that evaluates hormone replacement benefits in relation to cardiovascular disease risk in menopausal women.

The Framingham Study was the first prospective clinical cohort study to establish a risk correlation between menopause and coronary artery disease independent of the natural or surgical mechanisms of menopause ${ }^{41}$.

Less than one decade later, Stampfer and co-workers published their first analysis of the Nurses' Health Study ${ }^{42}$, which was later expanded to include a total of 48,000 healthy postmenopausal women followed for a 10 -year period ${ }^{43}$. In this prospective cohort study, the authors showed that women undergoing estrogen replacement therapy had a significant $50 \%$ reduction in the coronary artery disease development rate (and 50\% in the cardiac death rate, as well) when compared to other women who had never used estrogen.

Shortly after the nurses' study, Bush et al. ${ }^{44}$ published findings from another prospective cohort study, the Lipid Research Clinics Study, which included 2270 women, whose ages ranged from 40 to 69 years, and who were either healthy or had coronary artery disease. The authors observed a reduction of more than $60 \%$ in coronary mortality in women on estrogen replacement therapy compared to those not using the hormone in an average follow-up of 8.5 years. The reduction was more pronounced in those with known coronary artery disease. 
Analyzing all of the prospective cohort studies of estrogen use in menopausal women, Stampfer and Colditz ${ }^{40}$ and Grodstein and Stampfer ${ }^{2}$ concluded that those undergoing hormone replacement had a $45 \%$ reduction in the risk of developing coronary artery disease when compared to those who had used it in the past or had not used it at all $(95 \%$ confidence interval $=30 \% ; 56 \%)$. However, it should be emphasized that in none of these studies estrogen use was randomized.

More recently, Henderson et al. ${ }^{45}$ in the Leisure World cohort study showed a significant $50 \%$ reduction in the incidence of acute myocardial infarction in almost 9,000 female users and non-users of estrogen replacement therapy. Falkborn et al. also demonstrated a significant $50 \%$ reduction in the incidence of infarction with the use of estrogen combined with progesterone and a $26 \%$ reduction with estrogen alone ${ }^{46}$.

The effect of hormone replacement therapy on the incidence of stroke in menopausal women is not yet well established. This occurrence of stroke has not been modified by estrogen use in the large Nurses' Health study ${ }^{43}$ and in the meta-analysis by Grady et al. ${ }^{47}$. This fact is in accordance with the observation of similar prevalences of hypertension among female estrogen users and nonusers in the Framingham, Nurses' Health, and Lipid Research Clinics Follow-up studies ${ }^{48}$. However, another cohort study revealed a reduction of almost $50 \%$ in the incidence of stroke and mortality due to stroke in female estrogen users ${ }^{45,49}$. Two other studies also showed a reduction in the occurrence of stroke, not only when estrogen was used, but when it was combined with progesterone as well ${ }^{50,51}$.

The chronic effects of estrogen replacement therapy on the blood pressure of menopausal women are not yet completely understood. Although some studies show no pressure changes ${ }^{16,52}$, others reveal increases ${ }^{53}$ or decreases ${ }^{54,55}$. These disparate results are certainly due to study methodological bias (case-control, cohort, and retrospective) clearly indicating the necessity for prospective, randomized, and placebo-controlled studies.

The mechanisms of estrogen therapy that cause beneficial effects in cardiac morbidity and mortality in postmenopausal women are not yet well understood, but there are many explanations for them (table I), which will be discussed in the following section.

Table I - Proposed mechanisms justifying the beneficial use of estrogen replacement therapy in coronary artery disease risk, morbidity and mortality, in postmenopausal women

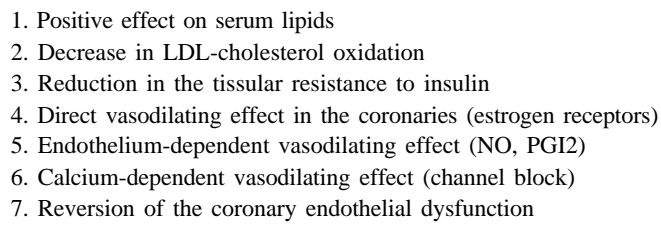

\section{Effects in lipid and carbohydrate metabolism}

Estrogen replacement causes significant changes in lipid serum levels in postmenopausal women. A 5-10\% increase in HDL-cholesterol and a 10-15\% decrease in LDLcholesterol are observed, and VLDL-cholesterol and triglycerides increase $10-15 \%{ }^{56-58}$. Furthermore, beneficial effects in $\mathrm{Lp}$ (a) apolipoprotein and in LDL-cholesterol oxidation have been seen in some studies ${ }^{59-61}$. It is believed that, in postmenopausal women, $50 \%$ of the protective effects against development of coronary artery disease with estrogen therapy are due to these serum lipid changes ${ }^{62}$.

Nabulsi et al. ${ }^{59}$ observed in a cohort study of almost 5,000 postmenopausal women that those using estrogen had higher levels of HDL-cholesterol and triglycerides and lower levels of LDL-cholesterol than the non-users, indicating a $42 \%$ risk reduction for the development of coronary artery disease.

The Postmenopausal Estrogen/ Progestin Interventions (PEPI) study is the first large prospective, randomized, double blind, placebo-controlled study that analyses the effects of estrogen replacement therapy, with or without progesterone addition, on morbidity and mortality and in clinical and laboratory parameters of 875 healthy menopausal women. The initial results have shown that all hormone replacement regimens produce beneficial effects in serum lipids ${ }^{63}$. Significant blood pressure changes were not observed in the patients of this study.

The beneficial effects of hormone replacement on carbohydrate metabolism in postmenopausal women observed by Barrett-Connor and Laakso ${ }^{64}$ - decrease in insulinemia and glycemia - possibly contribute to the reduction of the occurrence of coronary artery disease, but at this time, this is nothing more than an inference.

The addition of progesterone to estrogen therapy in postmenopausal women tends to reduce the effect of that therapy on the lipid profile ${ }^{58,63}$. However, Nabulsi et al. ${ }^{59}$ showed beneficial effects not only in lipidemia but also in insulinemia, when progesterone is cyclically administered.

\section{Effects on coronary atherosclerosis}

Some authors investigated the possible beneficial effects of hormone replacement therapy on coronary atherosclerosis.

Adams et al. ${ }^{65}$ conducted a randomized, placebocontrolled study of a group of ovariectomized monkeys given a diet rich in lipids and randomized into either an estrogen or a placebo group. A decrease of one half was observed in the grade of coronary atherosclerosis of those given estrogen.

Retrospective case-controlled studies in women using cinecoronary angiography demonstrated that estrogen use was independently predictive not only of the existence of coronary artery disease ${ }^{66,67}$ and its higher angiographic severity ${ }^{68}$, but also of survival at the end of a 10 -year follow-up period in those with coronary obstructions ${ }^{69}$. 
These pathologic and angiographic studies provide evidence that strengthen the cause-effect relationship between the beneficial changes observed in the lipid profile of postmenopausal women using estrogen and the reduction of coronary artery disease and the incidence of cardiac events observed in cohort studies.

\section{Effects in coronary vasomotion}

Some recent evidence suggests that the beneficial effects of estrogen use in postmenopausal women may be due not only to antiatherosclerotic mechanisms.

Studies have demonstrated that estrogen has a direct effect on coronary artery vasomotor function, causing vasodilatation ${ }^{19,70}$, as seen in other organs ${ }^{17,18}$. The intracoronary injection of acetylcholine causes a similar effect, which is mediated by the endothelial release of nitric oxide; however, this response turns into vasoconstriction ATT when there is coronary atherosclerosis, characterizing the endothelial dysfunction ${ }^{71}$.

Experiments conducted in ovariectomized monkeys, which were chronically fed with a lipid rich diet, showed coronary vasoconstrictive response to acetylcholine administration ${ }^{72,73}$. When these monkeys received an estrogen pretreatment, acutely ${ }^{73}$ or chronically ${ }^{72}$, the response to acetylcholine was vasodilatation, suggesting that the hormone have a rapid and possibly direct effect in the atherosclerotic coronary arteries, reversing the endothelial dysfunction. However, the idea of an effect mediated by nitric oxide release (or facilitation of its action), or inhibition of vasoconstrictive agents (for example, endothelin), or both can not be discarded ${ }^{73}$.

Recently, three placebo-controlled studies carried out during cardiac catheterization in postmenopausal women with coronary atherosclerosis confirmed the previous observations in monkeys, showing reversion of the paradoxical vasoconstriction induced by acetylcholine with acute estrogen use ${ }^{74-76}$. In one of these studies ${ }^{75}$, estrogen administration also resulted in coronary vasodilatation and in flow increase at the basal state (preacetylcholine).

These data suggest that beneficial and protective effects of hormone replacement in postmenopausal women may be due, at least partially, to its vasodilating action and coronary vasomotion normalization in cases with endothelial dysfunction.

A small clinical study ${ }^{77}$, which supports previous findings, was carried out in postmenopausal women presenting with symptomatic coronary artery disease and ischemic response to exercise. It showed a mild increase in the development time for a $1 \mathrm{~mm}$ downslope of the ST segment and in the total exercise time with the use of sublingual estrogen, when compared to placebo.

\section{Adverse effects of menopausal hormone replacement}

Despite all beneficial effects of estrogen replacement therapy (with or without progesterone) in the cardiovas- cular system and in the carbohydrate-lipid metabolism of menopausal women, this hormone use can have side effects that should be discussed.

Estrogen use without progesterone in nonhysterectomized women has a dose- and time-dependent risk of endometrial cancer 2-4 times higher than that observed in hormone nonusers ${ }^{3,78-80}$. This relative risk seems to be reduced to very low values when progesterone is added, and this reduction seems also to be dose- and time-dependent ${ }^{3,81,82}$. In addition, some case-control studies revealed less aggressiveness and a lower mortality rate from endometrial carcinoma occurring in estrogen users, when compared with non-users ${ }^{3}$.

So far, the researchers have not agreed on a possible risk of breast cancer development in estrogen replacement users ${ }^{3,78,83-86}$. Although a meta-analysis of case-controlled studies did not show a higher risk ${ }^{84}$, another study ${ }^{85}$ revealed a relative risk of 1.3 after 15 years of continuous estrogen use. In another study by Bergkvistet al. ${ }^{87}$, despite the higher incidence of breast carcinoma observed in hormone replacement users, the breast cancer mortality was similar to or lower than that of non-users, supporting other study results ${ }^{45,86}$. Use of progesterone in conjunction with estrogen has also shown inconsistent results regarding the incidence of cancer ${ }^{3}$.

Other undesirable side effects of estrogen use in postmenopausal women are the development (or recurrence) of gallstones and acute cholecystitis, and the reappearance of vasomotor headache ${ }^{58}$.

Finally, estrogen use significantly reduces the incidence of osteoporosis and, consequently, the fractures often observed in postmenopausal women ${ }^{58}$.

\section{Hormone replacement therapy: risks versus benefits}

As already seen all the beneficial and harmful effects of estrogen use associated or not with progesterone in postmenopausal women were obtained by cohort or casecontrolled observational studies and their meta-analysis. Even though several authors had tried to avoid the influence of methodological bias in their studies, attempting to control some confusing variables, adjusting them to the results, or both of these, it is necessary to be cautious in the final interpretation. Therefore, only by means of prospective, randomized, double blind, and placebo-controlled studies will it be possible to know if hormone replacement therapy actually has beneficial effects on morbidity and mortality in postmenopausal women, and also the risks deriving from its use. In order to answer these questions, some studies are being carried out and results have recently been published ${ }^{63}$, but some years will still be necessary before the presentation of the effects on morbidity and mortality.

Meanwhile, some authors using data derived from cohort studies estimate the effects of hormone replacement therapy on mortality. Henderson et al. ${ }^{88}$ applied relative risks of estrogen use of 0.5 for coronary artery disease 
development, of 0.4 for osteoporotic fractures, of 1.1 for breast cancer, of 1.5 for cholelithiasis, and of 2.0 for endometrial cancer. Based on these risks, they estimated mortality in women taking $0.625 \mathrm{mg}$ of conjugated estrogen daily, at the age of 50 and being observed until the age of 75 . The mortality variation with estrogen use compared to that of nonuse was -5250 deaths due to coronary artery disease in 100,000 treated women, -563 deaths due to osteoporotic fractures, +187 deaths due to breast cancer, +2 deaths due to cholelithiasis and +63 deaths due to endometrial cancer. The algebraic sum of these figures gives a variation of the estimated global mortality of -5561 (or $-41 \%$ ) with the use of estrogen. This dramatic reduction in global mortality would be due not only to the elevated number of coronary artery disease cases observed in these women, but also to the elevated mortality of the coronary artery disease itself, causing a relative risk of 0.5 to be translated into a huge number of spared lives. Even though endometrial cancer has a relative (but inverse) risk similar to that of coronary artery disease, it causes a number of deaths 100 times lower, because of its lower occurrence relative to coronary artery disease.

In a similar way, utilizing a meta-analysis of the different published studies, Grady and co-workers ${ }^{47}$ estimated the gain in years of life with hormone replacement therapy. These authors predicted that a 50-year-old white woman would have a $46 \%$ chance of developing coronary artery disease during the rest of her life and $31 \%$ of dying from it. Estrogen replacement therapy would reduce mortality in such women by ATT $45 \%$. These figures are compared to those estimates of other pathologies related to menopause and hormone replacement. Thus, stroke would occur in $20 \%$ of these women and stroke mortality would be $8 \%$, but estrogen therapy would not change these numbers. In regard to osteoporotic fracture (hip fracture), the risk would be $15 \%$, and mortality $1.5 \%$, and hormone replacement would reduce both by ATT $25 \%$. For breast cancer, its probability of occurrence in these women would be $10 \%$ and mortality $3 \%$, and the hormone replacement therapy would increase both to $25 \%$. Finally, the development rate of endometrial cancer would be $2.6 \%$ and mortality $0.3 \%$, and estrogen use without progesterone would increase the risk by ATT $800 \%$ and the mortality by ATT $300 \%$. Based on these numbers, the authors estimated that a white woman who enters menopause and does not have cardiac or gynecologic risk factors would have an average life expectancy of 82.3 years. With estrogen replacement, she would gain 0.9 years. However, a woman with coronary artery disease risk factors would have an average life expectancy of 79.6 years and would gain 1.5 years with estrogen replacement therapy and 1.6 years with estrogen in combination with progesterone. Finally, a woman known to have coronary artery disease would have an average life expectancy of 76 years and would gain 2.1 years with estrogen use and 2.2 years when an association of estrogen and progesterone is used. Even a woman with breast cancer risk (strong family history, risk around 20\%) and with an average life expectancy of 82.3 years, would gain 0.7 years with estrogen therapy and 0.8 years with combined estrogen and progesterone.

\section{Final conclusions}

All data discussed above strongly suggest that hormone replacement therapy in postmenopausal women has significant beneficial effects on morbidity and mortality, especially that with coronary causes, that supercedes the risk of harmful side-effects. The dramatic reduction in cardiac mortality seems to have a significant impact on general mortality, despite the increased chances of endometrial and breast cancer development. This impact is maximal in women with high risk of coronary artery disease or in those already with the disease. The global mortality reduction would manifest itself in the form of an increase in life expectancy of treated women. However, it is important to emphasize that these data are based on knowledge obtained from studies considered sub-optimal, from the methodological point of view. Despite this, their results are consistent enough to allow the recommendation of estrogen replacement, with or without progesterone, in postmenopausal women, especially for those considered at high cardiac risk ${ }^{89}$. Prospective, randomized and controlled studies that are currently underway should bring, in the coming years, final data on this subject so anxiously awaited.

\section{Addendum}

After the submission of this manuscript, results from the Heart and Estrogen/Progestin Replacement Study (HERS) were published (Hulley et al. JAMA 1998; 280: 605613). This prospective, randomized, single-blinded, placebocontrolled trial compared the combined use of $0.625 \mathrm{mg}$ of estrogen and $2.5 \mathrm{mg}$ of progesterone in 2,763 postmenopausal women (mean age $=66.7$ years, mean last menstruation $=18$ years ago) with known coronary artery disease. The study subjects were followed for four years. No significant differences in cardiac and non-cardiac death, non-fatal acute myocardial infarction or need of myocardial revascularization was observed between treated and non-treated patients. Also, no significant increase in breast or endometrial cancer rates was seen in treated patients, but a significantly increased rate (3-fold) of thromboembolic phenomena was detected in the treated group versus the placebo group.

The negative results of this first randomized trial of secondary prevention indicates that up to four years of hormonal replacement in elderly postmenopausal women does not change the natural history of their coronary artery disease. However some questions can be raised: 1) Would four years of late hormonal replacement be enough to disclose beneficial effects?; 2) Can the results of HERS be extrapolated to a younger group of postmenopausal women with coronary artery disease in whom life expectancy is greater than that of the study population?; 3) Would the tendency of a lower rate of non-fatal infarctions seen in treated patients in the last two years of the study turn out to be significant with a longer follow-up, therefore also changing cardiac mortality? 
HERS brings out important information for cardiologists and gynecologists, but also raises questions about the validity of transposing these data to clinical practice where physicians usually deal with younger women with recent onset of menopause and, consequently, with short exposure to reduced levels of estrogen (and its adverse cardiovascular actions). Even if coronary artery disease is already established, it is possible that in this group of women the hormonal therapy will have a more favorable effect than the one seen (or not seen) in the elderly women with significant coronary disease studied in HERS. It is also expected that a greater life expectancy (and, consequently, a longer follow-up) may be necessary to demonstrate a positive effect of estrogen therapy in women with coronary artery disease.

\section{References}

1. Kannel WB, Hjortland MC, McNamara PM et al-Menopause and the risk of cardiovascular disease: the Framingham Study. Ann Intern Med 1976; 85: 447-55.

2. Grodstein F, Stampfer MJ - Epidemiologic studies on ERT and cardioprotection: state of the art on HRT and cardiovascular disease. In: Crosignani PG et al (Ed) Women's Health in Menopause: Behavior, Cancer, Cardiovascular Disease, Hormone Replacement Therapy. Dordrecht: Kluwer Academic Publishers, 1994: 133-147.

3. Sismondi P, Biglia N, De Fabiani E et al - Hormone replacement therapy and gynecologic cancers. In: Crosignani PG et al (Ed). Women's health in menopause: behavior, cancer, cardiovascular disease, hormone replacement therapy. Dordrecht: Kluwer Academic Publishers, 1994: 197-206.

4. Kayan AR, Stemby NH, Uemura K et al - Atherosclerosis of the aorta and coronary arteries in five towns. Bull Who 1976; 53: 485-91.

5. Rich-Edwards JW, Manson JE, Hennekens CH, Buring JE - The primary prevention of coronary heart disease in women. N Engl J Med 1995; 332: 1758-66.

6. Greenland P, Reicher-Reiss H, Goldbourt U, Behar S - In-hospital and 1-year mortality in 1,524 women after myocardial infarction: comparison with 4,315 men. Circulation 1991; 83: 484-91.

7. Bassan R, Pimenta L, Postch A et al - Is female gender an independent risk factor for hospital mortality in acute myocardial infarction? J Am Coll Cardiol 1998; 31(suppl C): 403C.

8. White HD, Barbash GI, Modan M et al - After correcting for worse baseline characteristics, women treated with thrombolytic therapy for acute myocardial infarction have the same mortality and morbidity as men except for higher incidence of hemorrhagic stroke. Circulation 1993; 88 (part 1): 2097-103.

9. Kannel WB - Status of risk factors and their consideration in antihypertensive therapy. Am J Cardiol 1987; 59: 80A-90A.

10. Carlson LA, Bottinger LE - Risk factors for ischemic heart disease in men and women: results of the 19-year follow-up of the Stockholm Prospective Study. Acta Med Scand 1985; 218: 207-11.

11. Rowland M, Roberts J - Blood pressure levels of persons 6-74 years: United States 1976-1980. National Health and Nutrition Examination Survey II. NCHS Advance Date. Vital and Health Statistics of the National Center for Health Statistics, number 84. US Department of Health and Human Services, Washington, 1982.

12. Lerner DJ, Kannel WB - Patterns of coronary heart disease morbidity and mortality in the sexes: a 26-year follow-up of the Framingham population. Am Heart J 1986; 111: 383-90.

13. Wolf PA, D'Agostino RB, Belanger AJ, Kannel WB - Probability of stroke: a risk profile from the Framingham Study. Stroke 1991; 22:312-18.

14. Staessen J, Bulpitt CJ, Fagard R et al - The influence of menopause on blood pressure. J Hum Hypertens 1989; 3: 427-33.

15. Posner BM, Cupples LA, Miller DR et al - Diet, menopause and serum cholesterol levels in women: the Framingham Study. Am Heart J 1993; 125: 483-9.

16. Matthews KA, Meilahn E, Kuller LH et al - Menopause and risk factors for coronary heart disease. N Engl J Med 1989; 321: 641-6.

17. Magness RR, Rosenfeld CR - Local and systemic 17ß-estradiol: effect on uterine and systemic vasodilatation. Am J Physiol 1989; 256: E536-E542.

18. Pines A, Fisman EZ, Levo Y et al - The effects of hormone replacement therapy in normal postmenopausal women: measurements of Doppler derived parameters of aortic flow. Am J Obstet Gynecol 1991; 164: 806-12.

19. McGill HC - Sex steroid hormone receptors in the cardiovascular system. Postgrad Med 1989; 85: 64-8.

20. Van Buren GA, Yang D, Clark KE - Estrogen-induced uterine vasodilatation is antagonized by L-nitroarginine methyl ester, an inhibitor of nitric oxide synthesis. Am J Obstet Gynecol 1992; 166: 828-33.

21. Williams JK, Adams MR, Klopfenstein HS - Estrogen modulates responses of atherosclerotic coronary arteries. Circulation 1990; 81: 1680-7.
22. Steinleitner A, Stanczyk FZ, Levin JH et al - Decreased in vitro production of 6 keto-prostaglandin F1 alpha by uterine arteries from postmenopausal women. Am J Obstet Gynecol 1989; 161: 1677-81.

23. Polderma KH, Stenhouwer CDA, Van Kamp GJ et al - Influence of sex hormones on plasma endothelin levels. Ann Intern Med 1993; 118: 429-32.

24. Collins P, Rosano GMC, Jiang C et al - Cardiovascular protection by oestrogen: a calcium antagonist effect? Lancet 1993; 341: 1264-5.

25. Chester A, Jiang C, Sarrel PM et al - 17ß-estradiol induces endotheliumindependent relaxation in human coronary arteries in vitro. Circulation 1993; 88(suppl I): I-78.

26. La Rosa JC, Hunninghake D, Bush D et al - The cholesterol fact: a summary of the evidence relating dietary fats, serum cholesterol and coronary artery disease: joint statement by the American Heart Association and the National Heart, Lung and Blood Institute. Circulation 1990; 81: 1721-33.

27. Castelli WP, Garrison RJ, Wilson PWF et al - Incidence of coronary heart disease and lipoprotein cholesterol levels: the Framingham Study. JAMA 1986; 256: $2835-8$.

28. Bush TL, Criqui MN, Cowan LD et al - Cardiovascular disease mortality in women: results from the Lipid Research Clinics Follow-up Study. In: Eaker ED, Packard B, Wenger NK et al (Ed). Coronary Heart Disease in Women. Proceedings of a NIH Workshop. Haymarket Doyma, New York, 1987; 106-11.

29. Levy RI, Brensike JF, Epstein SE et al - The influence of changes in lipid values induced by cholestyramine and diet on progression of coronary artery disease: results of the NHLBI Type II Coronary Intervention Study. Circulation 1984; 69: 325-37.

30. Kane JP, Malloy MJ, Ports TA et al - Regression of coronary atherosclerosis during treatment of familial hypercholesterolemia with combined drug regimens. JAMA 1990; 264: 3007-12.

31. Rosenhamer G, Carlson LA - Effect of combined clofibrate-nicotinic acid treatment in ischemic heart disease. Atherosclerosis 1980; 37: 129-42.

32. Muldoon MF, Manuck SB, Matthews KA - Lowering cholesterol concentrations and mortality: a quantitative review of primary prevention trials. Br Med J 1990; 301: 309-14.

33. Bonithon-Kopp C, Scarabin PY, Dame B et al-Menopause-related changes in lipoprotein and some other cardiovascular risk factors. Int J Epidemiol 1990; 19: $42-8$.

34. Jensen J-Effects of sex steroids on serum lipids and lipoproteins. Baillieres Clin Obstet Gynaecol 1991; 5: 867-87.

35. Kannel WB, Gordon T - Cardiovascular effects of the menopause. In: Mishell DR Jr (Ed). Menopause physiology and pharmacology. Year Book Medical, Chicago, 1987: 91.

36. Kannel WB, McGee DL - Diabetes and cardiovascular disease: the Framingham Study. JAMA 1979; 241: 2035-8.

37. Barret-Connor E, Wingard DL - Sex differential in ischemic heart disease mortality in diabetics: a prospective population-based study. Am J Epidemiol 1983; 118: 489-96.

38. Proudler AJ, Felton C, Stevenson JC - Aging and the plasma insulin, glucose and $\mathrm{C}$-peptide response to intravenous glucose in postmenopausal women. Clin Sci 1992; 83: 489-94.

39. Razay $\mathrm{G}, \mathrm{Heaton} \mathrm{KW}$, Bolton $\mathrm{CH}$ - Coronary heart disease risk factors in relation to menopause. Q J Med 1992; 85: 889-96.

40. Stampfer MJ, Colditz GA - Estrogen replacement therapy and coronary heart disease: a quantitative assessment of the epidemiologic evidence. Prev Med 1991; 20: 47-63.

41. Gordon T, Kannel WB, Hjortland MC et al - Menopause and coronary heart disease: the Framingham Study. Ann Intern Med 1978; 89: 157-61.

42. Stampfer MJ, Willett WC, Colditz GA et al - A prospective study of postmenopausal estrogen therapy and coronary heart disease. N Engl J Med 1985; 313 : 1044-9. 
43. Stampfer MJ, Colditz GA, Willett WC et al - Postmenopausal estrogen therapy and cardiovascular disease: ten-year follow-up from the Nurses' Health Study. N Engl J Med 1991; 325: 756-62.

44. Bush TL, Barrett-Connor E, Cowan LD et al - Cardiovascular mortality and noncontraceptive use of estrogen in women: results from the Lipid Research Clinics Program Follow-up Study. Circulation 1987; 75: 1102-109.

45. Henderson BE, Paganini-Hill A, Ross RK - Decreased mortality in users of estrogen replacement therapy. Arch Intern Med 1991; 151: 75-8.

46. Falkeborn M, Persson I, Adami HO et al - The risk of acute myocardial infarction after oestrogen and oestrogen-progestogen replacement. Br J Obstet Gynecol 1992; 99: 821-8.

47. Grady D, Rubin Sm, Petitti DB et al - Hormone therapy to prevent disease and prolong life in postmenopausal women. Ann Intern Med 1992; 117: 1016-39.

48. Hall PM - Hypertension in women. Cardiology 1990; 77(suppl 2): 25-30.

49. Paganini-Hill A, Ross RK, Henderson BE - Postmenopausal oestrogen treatment and stroke: a prospective study. Br Med J 1988; 297: 519-22.

50. Thompson SG, Meade TW, Greenberg G - The use of hormonal replacement therapy and the risk of stroke and myocardial infarction in women. J Epidemiol Community Health 1989; 43: 173-8.

51. Falkeborn M, Persson I, Terent A et al - Hormone replacement therapy and risk of stroke. Arch Intern Med 1993; 153: 1201-209.

52. Hassager C, Riis BJ, Strom V, Guyene TT, Christiansen C-The long-term effect of oral and percutaneous estradiol on plasma renin substrate and blood pressure. Circulation 1987; 76: 753-8.

53. Pfeffer RI, Kurosaki TT, Charlton SK - Estrogen use and blood pressure in later life. Am J Epidemiol 1979; 110: 469-76.

54. Luotola $\mathrm{H}-$ Blood pressure and hemodynamics in postmenopausal women during 17ß-estradiol substitution. Ann Clin Res 1983; 15(suppl 38): 1-121.

55. Christiansen C, Christiansen MS, Hagen C, Stocklund KE, Transbol I-Effects of natural estrogen/progestogen and thiazide on coronary risk factors in normal postmenopausal women. A 2-year double-blind placebo study. Acta Obstet Gynecol Scand 1981; 60: 407-12.

56. Sacks FM, Walsh BW - The effects of reproductive hormones on serum lipoproteins: unresolved issues in biology and clinical practice. Ann NY Acad Sci 1990; 592: 272-85.

57. Walsh BW, Schiff I, Rosner B et al - Effects of postmenopausal estrogen on the concentration and metabolism of plasma lipoproteins. N Engl J Med 1991; 325: 1196-204.

58. Belchetz PE - Hormonal treatment of postmenopausal women. N Engl J Med 1994; 330: 1062-71.

59. Nabulsi AA, Folsom AR, White A et al-Association of hormone-replacement therapy with various cardiovascular risk factors in postmenopausal women. $\mathrm{N}$ Engl J Med 1993; 328: 1069-75.

60. Sack MN, Rader DJ, Cannon RO - Estrogen and inhibition of oxidation of lowdensity lipoproteins in postmenopausal women. Lancet 1994; 343: 269-70.

61. Keaney JF, Shwaery GT, Xu A et al - Preservation of endothelial function in hypercholesterolemia through the antioxidant properties of estrogens. Circulation 1993; 88(suppl I): I-79.

62. Barrett-Connor E, Bush T - Estrogen and coronary heart disease in women. JAMA 1991; 265: 1861-7.

63. The Writing Group for the PEPI Trial - Effects of estrogen or estrogen/ progestin regimens on heart disease risk factors in postmenopausal women: the Postmenopausal Estrogen/Progestin Interventions (PEPI) Trial. JAMA 1995; 273: 199-208.

64. Barrett-Connor E, Laakso M - Ischemic heart disease risk in postmenopausal women. Effects of estrogen use on glucose and insulin levels. Arteriosclerosis 1990; 10: 531-4.

65. Adams MR, Kaplan JR, Klopfenstein HS - Inhibition of coronary atherosclerosis by $17 ß$-estradiol in ovariectomized monkeys. Lack of an effect of added progesterone. Arteriosclerosis 1990; 10: 1051-7.

66. Sullivan JM, Vander-Zwaag R, Lemp GF et al-Postmenopausal estrogen use and coronary atherosclerosis. Ann Intern Med 1988; 108: 358-63.
67. McFarland KF, Boniface ME, Homung CA et al - Risk factors and noncontraceptive estrogen use in women with and without coronary artery disease. Am Heart J 1989; 117: 1209-214.

68. Gruchow HW, Anderson AJ, Barboriak JJ et al - Postmenopausal use of estrogen and occlusion of coronary arteries. Am Heart J 1988; 115: 954-63.

69. Sullivan JM, Vander-Zwaag R, Hughes JP et al - Estrogen replacement and coronary artery disease: effect on survival in postmenopausal women. Arch Intern Med 1990; 150: 2557-62.

70. Fogelberg M, Yesterquist O, Dicfalusy P et al - Experimental atherosclerosis: effects of estrogen and atherosclerosis on thromboxane and prostacyclin formation. Europ J Clin Invest 1990; 20: 105-10.

71. Ludmer PL, Selwyn AP, Shook TL et al - Paradoxical vasoconstriction induced by acetylcholine in atherosclerotic coronary arteries. N Engl J Med 1986; 315: 1046-51.

72. Williams JK, Adams MR, Klopfenstein HS - Estrogen modulates responses of atherosclerotic coronary arteries. Circulation 1990; 81: 1680-7.

73. Williams JK, Adams MR, Herington DM, Clarkson TB - Short-term administration of estrogen and vascular response of atherosclerotic coronary arteries. J Am Coll Cardiol 1992; 20: 452-7.

74. Collins P, Rosano GMC, Adamopoulos S et al - Reversal of acetylcholineinduced vasoconstriction by intracoronary administration of $17 \mathrm{~B}$-estradiol in menopausal women with coronary artery disease. Circulation 1993; 88: I-589.

75. Reis SE, Gloth ST, Blumenthal RS et al - Ethinyl estradiol acutely attenuates abnormal coronary vasomotor responses to acetylcholine in postmenopausal women. Circulation 1994; 89: 52-60

76. Lieberman EH, Gerhard M, Yeung AC et al - Estrogen improves coronary vasomotor responses to acetylcholine in postmenopausal women. Circulation 1993; 88(suppl I): I-79.

77. Rosano GMC, Sarrel PM, Poole-Wilson PA, Collins P-Beneficial effect of estrogen on exercise-induced myocardial ischemia in women with coronary artery disease. Lancet 1993; 342: 133-6.

78. Hunt K, Vessey M, McPherson K, Coleman M - Long-term surveillance of mortality and cancer incidence in women receiving hormone replacement therapy. Br J Obstet Gynecol 1987; 94: 620-35.

79. Smith DC, Prentice R, Thompson DJ, Hermann WL - Association of exogenous estrogen and endometrial carcinoma. N Engl J Med 1975; 293: 1164-7.

80. Ziel HK, Finkle WD - Increased risk of endometrial carcinoma among users of conjugated estrogens. N Engl J Med 1975; 293: 1167-70.

81. Persson I, Adami HO, Bergkvist L et al-Risk of endometrial cancer after treatment with estrogens alone or in conjunction with progestogens: results of a prospective study. MBJ 1989; 298: 147-51.

82. Voigt LF, Weiss NS, Chu J et al - Progestogen supplementation of exogenous oestrogens and risk of endometrial carcinoma. Lancet 1991; 338: 274-7.

83. Bergkvist L, Adami HO, Persson I, Hoover R, Schairer C - The risk of breast cancer after estrogen and estrogen progestin replacement. N Engl J Med 1989; 321: 293-7.

84. Dupont WD, Page DL - Menopausal estrogen replacement therapy and breas cancer. Arch Intern Med 1991; 151: 67-72.

85. Steinberg KK, Thacker SB, Smith SJ et al-A meta-analysis of the effect of estrogen replacement therapy on the risk of breast cancer. JAMA 1991; 265: 1985-90 (erratum: JAMA 1991; 266: 1362)

86. Colditz GA, Stampfer MJ, Wilett WC et al - Prospective study of estrogen replacement therapy and risk of breast cancer in postmenopausal women. JAMA 1990; 264: 2648-53

87. Bergkvist L, Adami HO, Persson I, Bergstrom R - Prognosis after breast cancer diagnosis in women exposed to estrogen and estrogen-progestogen replacement therapy. Am J Epidemiol 1989; 130: 221-8.

88. Henderson BE, Ross RK, Paganini-Hill A, Mack TM - Estrogen use and cardiovascular disease. Am J Obstet Gynecol 1986; 154: 1181-8.

89. American College of Physicians - Guidelines for counseling postmenopausal women about preventive hormone therapy. Ann Intern Med 1992; 117: 1038-41. 